\title{
Use of Chemical Clamps in Denaturing Gradient Gel Electrophoresis: Application in the Detection of the Most Frequent Mediterranean $\beta$-Thalassemic Mutations
}

\section{Eric Fernandez, Thierry Bienvenu, François Desclaux Arramond, Kheira Beldjord, Jean Claude Kaplan, and Cherif Beldjord}

Institut National de la Santé et de la Recherche Médicale (INSERM) U 129, Institut Cochin de Genetique Moleculaire (ICGM), 75014, Paris Cedex, France
The most frequent molecular defects in genetic diseases are represented by point mutations. There is an increasing need for practical, efficient, and inexpensive ways to explore mutations responsible for these diseases. PCR has solved the problem of the target. When the precise site of a point mutation is not known, it is necessary to first determine the region harboring the defect. Six methods are currently available: single-strand conformation polymorphisms (SSCP), chemical cleavage, RNase mismatch cleavage, reaction of DNA heteroduplexes with a water-soluble carbodiimide, direct sequencing, and denaturing gradient gel electrophoresis (DGGE). To be used routinely, a method must be safe, simple, and of reasonable cost. The first five methods involve unsafe reagents (chemicals and radioactivity), but in some cases are relatively inexpensive. The last method, DGGE, is safe but very expensive, because of the high cost of the long GC sequence (from 30 to 80 nucleotides) that must be attached to the $5^{\prime}$ end of one of the primers. In addition, with such a clamp, the yield of primer is reduced drastically, increasing the cost of experiments. Chemical clamps (Appligène, Strasbourg, France) have been designed recently, allowing these difficulties to be overcome. Instead of adding a long GC-rich tail, the end of the DNA fragment can be stabilized by covalently linking both strands with a chemical agent. The best such agent currently available is psoralen (furocoumarin), ${ }^{(1)} \mathrm{a}$ photoactivatable intercalating agent. When irradiated, this intercalated polycyclic compound becomes covalently linked to the 5-6 double bonds of the complementary strands (particularly thymine). The substance is chemically fixed by the manufacturer (Appligéne) to the 5 ' end (including two adenines) of the primer to be clamped. This procedure represents a very attractive alternative to GC clamping, especially as most laboratories in the world do not have an oligonucleotide synthesizer. To extend this method, we tested it on known mutations responsible for $\beta$-thalassemia in the Mediterranean region. This disease is the most common recessive inherited disorder in Mediterranean populations, ${ }^{(2)}$ and in the last few years the molecular basis of $\beta$-thalassemia in this area, as well as in other populations, has been largely defined by cloning and sequencing or oligonucleotide analysis.
More than 110 different mutations, heterogeneously distributed, have been reported to cause this disease. ${ }^{(3,4)}$

Here, we propose the use of chemical clamps in combination with the DGGE method for a single-assay diagnosis of the most frequent $\beta$-thalassemic mutations encountered in Mediterranean countries. $^{(S)}$

\section{MATERIALS AND METHODS}

Peripheral blood samples were collected from $\beta$-thalassemic patients, and the genomic DNA was extracted by standard methods from nucleated cells. $\beta$-Thalassemia was always confirmed by family studies and standard techniques. ${ }^{(6)}$

A 429-bp fragment, running from -198 to +331 relative to the cap site was chosen to test a large proportion of the known thalassemic mutants, including the dominant ones in Mediterranean countries. The upstream primer was $5^{\prime}$ psoralen-AACATCACTTAGACCTCACC, and the downstream primer was $5^{\prime}$-ATCAGGAGTGGACAGATCCC-3' in exon 2. The psoralen derivative was attached to the $5^{\prime}$ end of the upstream primer by the manufacturer (Appligène). Reactions were performed in a volume of $100 \mu \mathrm{l}$ containing $67 \mathrm{~mm}$ Tris- $\mathrm{HCl}(\mathrm{pH} 8.8$ ), $16.6 \mathrm{mM} \mathrm{SO}_{4}\left(\mathrm{NH}_{4}\right)_{2}, 4.5 \mathrm{mM} \mathrm{MgCl}, 10$ $\mu l$ DMSO, $1 \mathrm{~mm}$ each of all four deoxynucleotides, $0.5 \mathrm{~mm}$ each of the primers, 2.5 unites of Taq polymerase (PerkinElmer Cetus), and $200 \mathrm{ng}$ of template DNA. Samples were heated at $94^{\circ} \mathrm{C}$ for 7 $\min$ and at $57^{\circ} \mathrm{C}$ for $2 \mathrm{~min}$ in the first round of denaturation and annealing. Forty cycles were then performed with denaturation for $50 \mathrm{sec}$ at $94^{\circ} \mathrm{C}$, annealing for $50 \mathrm{sec}$ at $57^{\circ} \mathrm{C}$, and elongation for $50 \mathrm{sec}$ at $72^{\circ} \mathrm{C}$. The DNA synthesis step of the final cycle at $72^{\circ} \mathrm{C}$ was extended to 7 min. The amplified DNA was then irradiated with a $365-\mathrm{nm}$ UV lamp for 15 min (maximum time given for this fragment). After irradiation, the PCR products were analyzed by DGGE. The gel apparatus is the same as initially described $^{(7)}$ (C.B.S. Scientific, Del Mar, CA). One-fifth of the amplified product was loaded onto a $6 \%$ polyacrylamide gel with a parallel gradient increasing linearly from $30 \%$ to $80 \%$ denaturant [100\% denaturant: $7 \mathrm{~m}$ urea, $40 \%$ formamide (vol/vol)] at $160 \mathrm{~V}(60 \mathrm{~mA})$ for $5 \mathrm{hr}$. The fragments were visualized by UV transillumination after ethidium bromide staining. Computer programs, 
kindly provided by L. Lerman and colleagues, were used to predict melting behavior of this fragment with an optimal oligonucleotide clamp. ${ }^{(8)}$ These algorithms allowed us to define the best denaturant concentration range, as well as the optimum electrophoresis time. The migration conditions were applied to the chemically clamped fragment without any modification. The two less stable melting domains, having melting temperatures within $10 \%$ denaturant range of each other, were explored together. To confirm the results, all mutations investigated in this study have been detected previously and defined by standard methods. ${ }^{(9,10)}$

\section{RESULTS AND DISCUSSION}

Thirty-five DNA samples from individuals heterozygous or compound heterozygous for $\beta$-thalassemic mutations localized $3^{\prime}$ to the cap site were analyzed in a single-blind study. In all cases, a characteristic pattern was observed with good separation and resolution. In general, for a heterozygous individual four bands were present on the denaturing gradient gel (Fig. 1). The two lower bands are the two different alleles. The two upper bands, melting early in denaturing gradient gel, are the result of heteroduplex formation between complementary strands of the two alleles. Heteroduplex formation occurs as an artifact of the PCR procedure. These bands aid in the interpretation of the gels by clearly identifying the heterozygous samples. As with GC-clamp-primer, in a few cases the PCR products were represented by three bands. An examples of this is shown in Figure 1A, lane 3. The mutated allele comigrates with the normal one on a denaturing gradient gel. However, the presence of a mutation is identified clearly by the presence of heteroduplex bands. In a few other cases, the two homoduplexes migrate at a different level in the gel while the heteroduplexes do not separate under these conditions (Fig. $1 B$, lanes $3,5,8$ ). A specific and characteristic pattern was obtained with the different mutations explored and their various associations. In comparison with a parallel investigation using ASO and direct sequencing, all of the results obtained in these 70 chromosomes were unambiguous.

In view of the problem raised by thalassemia, routine diagnosis and diag-

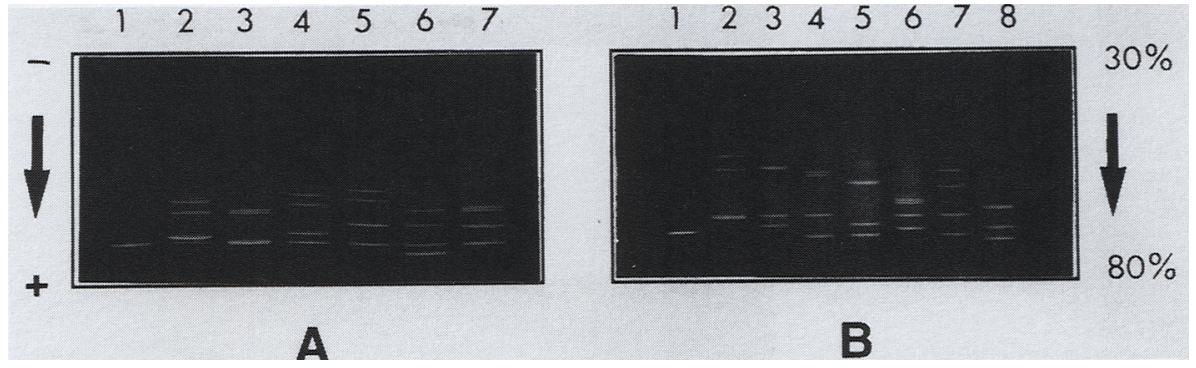

FIGURE 1 DGGE analysis of $\beta$-globin gene in heterozygous patients $(A)$ and in compound heterozygous patients $(B)$. (A) (Lane 1 ) Normal control; (lane 2) IVS-1 nucleotide $1 \mathrm{G} \rightarrow \mathrm{A}$; (lane 3) IVS-1 nucleotide $2 \mathrm{~T} \rightarrow \mathrm{A}$; (lane 4) IVS-1 nucleotide $5 \mathrm{G} \rightarrow \mathrm{A}$; (lane 5) IVS-1 nucleotide $10 \mathrm{G} \rightarrow \mathrm{A}$; (lane 6) IVS-1 nucleotide $6 \mathrm{~T} \rightarrow \mathrm{C}$; (lane 7) Co39 C $\rightarrow \mathrm{T}$. $(B)$ (Lane 1) Normal control; (lane 2) IVS-1 nucleotide $110 \mathrm{G} \rightarrow \mathrm{A} / \mathrm{Co} 39 \mathrm{C} \rightarrow \mathrm{T}$; (lane 3) IVS-1 nucleotide $110 \mathrm{G} \rightarrow \mathrm{A} / \mathrm{IVS}-1$ nucleotide $1 \mathrm{G} \rightarrow \mathrm{A}$; (lane 4) IVS-1 nucleotide $110 \mathrm{G} \rightarrow$ A/IVS-1 nucleotide $6 \mathrm{~T} \rightarrow \mathrm{C}_{\text {; }}$ (lane 5 ) IVS-1 nucleotide $1 \mathrm{G} \rightarrow$ A/IVS-1 nucleotide $6 \mathrm{~T} \rightarrow \mathrm{C}$; (lane 6) Co39 C $\rightarrow$ T/IVS-1 nucleotide $1 \mathrm{G} \rightarrow$ A; (lane 7 ) Co39 $\mathrm{C} \rightarrow$ T/IVS-1 nucleotide $6 \mathrm{~T} \rightarrow \mathrm{C}$; (lane 8 ) FS 41/42-CTTT/Co26 G $\rightarrow$ A hemoglobin E (HbE).

nostic screening are performed best by using denaturing gel electrophoresis. The method is rapid, does not involve radioactivity, and results are obtained after a single electrophoresis. Furthermore, our technique is suitable for single assay diagnosis and uses a short primer linking with a chemical clamp instead of adding a long GC-rich tail, thus reducing still further the overall cost and time. Taking into account both the price and the yield of primers, in our experience the cost of a single diagnosis is reduced from two- to fivefold. In Figure 1 we show that the two most frequent mutations in the Mediterranean basin (IVS-1 nucleotide $110 \mathrm{G} \rightarrow \mathrm{A}$; Co39 $\mathrm{C} \rightarrow \mathrm{T}$ ) give typical and easy-to-recognize patterns. These two thalassemic mutations are encountered most frequently by far, in France as well as in other European populations such as in Italy and Portugal. ${ }^{(5)}$ These mutations also seem to be predominant in North African populations, although so far only the urban areas of Tunisia and Algeria have been investigated partially. ${ }^{(1)}$ The same mutation frequency could be present in other Mediterranean populations that as of yet have been evaluated only partially. Between $50 \%$ and $75 \%$ of existing mutations are of one of these two types. By this simple procedure, we were also able to characterize other mutations located in the analyzed region (Fig. 1). The chemical clamps in DGGE, while applied here specifically for the diagnosis of common thalassemic mutations, have since been employed successfully in our laboratory to screen for other genes, particularly CFTR, p53, and Gs $\alpha$ protein (data not shown). Using psoralen clamps, the cost-efficiency ratio is sufficient. This makes DGGE widely applicable in screening for known mutants and polymorphisms as well as in locating regions of DNA bearing unknown mutations.

\section{ACKNOWLEDGMENTS}

This work was supported by INSERM U129 grants.

\section{REFERENCES}

1. Scott, B.R., M.A. Pathak, and G.R. Mohn. 1976. Molecular and genetic basis of furocoumarin reactions. Mutat. Res. 39: 2974.

2. Bunn, H.T. and B.G. Forget. 1986. Human hemoglobin: Molecular genetics and clinical aspects. pp. 223-321. W.B. Saunders Company, Philadelphia, PA.

3. Kazazian, H.H. Jr., and C.D. Boehm. 1988. Molecular basis and prenatal diagnosis of $\beta$ thalassemia. Blood 72: 1107-1116.

4. Huisman, T.H.J. 1990. $\beta$-Thalassemia repository. Hemoglobin 14: 661-675.

5. Cao, A., M. Goossens, and M. Pirastu. 1989. $\beta$-Thalassemia mutations in Mediterranean populations. Br. J. Haematol. 71: 309-312.

6. Adjrad, L., F. Rouabhi, A. Amara, R. Girot D. Labie, and M. Benabadji. 1985. La $\beta$ thalassemie homozygote en Algerie. Etude de cinquante cas. Presse Med. 14: 2089-2092.

7. Myers, R.M., T. Maniatis, and L.S. Lerman. 1987. Detection and electrophoresis. Methods Enzymol. 155: 501-527.

8. Sheffield, V.C., D.R. Cox, L.S. Lerman, and R.M. Myers. 1989. Attachment of a 
40-base pair $G+C$ rich sequence to genomic DNA fragments by the polymerase chain reaction results in improved detection of single-base changes. Proc. Natl. Acad. Sci. 86: 232-236.

9. Thein, S.L., J.S. Wainscoat, J.R. Lynch, D.J. Weatherall, M. Sampietro, and G. Fiorelli. 1985. Direct detection of $\beta^{\circ} 39$ thalassemic mutation with Mael. Lancet i: 1095.

10. Saiki, R.K., T.L. Bugawan, G.T. Horn, K.B. Mullis, and H.A. Erlich. 1986. Analysis of enzymatically amplified $\beta$ globin and HLA-DQ DNA with allele specific oligonucleotide probes. Nature 324: 163-166.

11. Bennani, C., R. Tamouza, F. Rouabhi, M. Benabadji, M. Malou, J. Elion, D. Labie, and C. Beldjord. 1993. The spectrum of $\beta$-thalassemia in Algeria: Possible origins of the molecular heterogeneity and a tentative diagnostic strategy. Br. J. Haematol. 84: 335-337.

Received May 24, 1993; accepted in revised form July 13, 1993. 


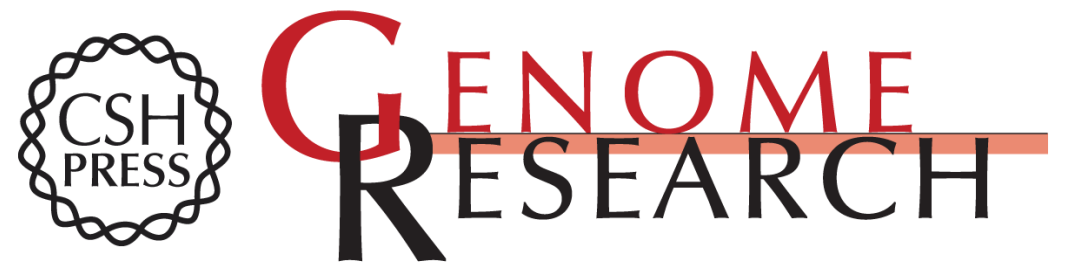

\section{Use of chemical clamps in denaturing gradient gel electrophoresis: application in the detection of the most frequent Mediterranean beta-thalassemic mutations.}

E Fernandez, T Bienvenu, F Desclaux Arramond, et al.

Genome Res. 1993 3: 122-124

Access the most recent version at doi:10.1101/gr.3.2.122

References This article cites 9 articles, 2 of which can be accessed free at: http://genome.cshlp.org/content/3/2/122.full.html\#ref-list-1

\section{License}

Email Alerting

Receive free email alerts when new articles cite this article - sign up in the box at the Service top right corner of the article or click here.

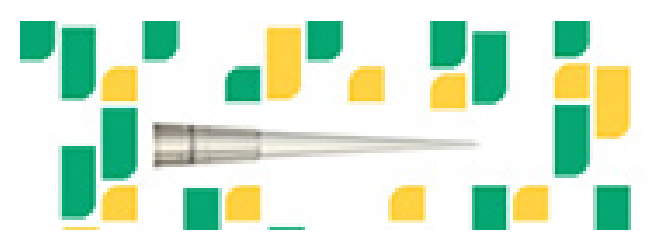

Focused on your science.

To subscribe to Genome Research go to:

https://genome.cshlp.org/subscriptions 